\title{
A CRITICAL STUDY OF 270 CASES OF DRY LABOR*
}

By Franklin A. Dorman, M.D., and E. C. Lyon, JR., M.D., New YorK, N. Y.

F VERY practitioner of obstetries has in his mind an indictment of Jary labor." The laity shares this prejudice. The writers of lextbooks frame their charges in no uncertain lones. Jewett says: "If by mischance early rupture of the membrane has occurred and the waters have drained away, such lahors are proverbially liable to be of long duration and prejudicial to mother and child." Cragin, in his textbook, page 209, says: "Sometimes rupture of the membrane occurs several days or even weeks before the onset of labor, but as a rule labor pains begin within twenty-four hours. Several cases have come under my observation in which, after the escape of liquor amnii, the long pressure upon the child and the entrance of air to the amniotic sac has apparently caused the death of the child and infection of the mother. It is my custom to start the induction of labor in a patient whose pains do not begin in twenty-four hours after the rupture of the membrane." This was a standing rule at the sloane Hospital at the time when the authors were residents there.

Dr. Lee states that "when the bag of waters ruptures before labor, especially in primipara, these are called dry labors and are usually long, tedious, and painful. Operative interference is often necessary in dry labors."

Wright states that "the so-called dry labor is, in a large proportion of cases, a protracted labor, nearly always accompanied by serious symptoms and frequently followed by disastrous results. Dangers to the mother are: exhaustion from long-continued pain, with tetanic contraction of the uterus, rupture of the uterus, laceration of the cervix, vagina, pelvic floor and perineum; various forms of fistulæ; post partum hemorrhage, pulmonary thrombosis, septicemia. The dangers to the child are chiefly asphyxiation and meningeal hemorrhage."

Peterson: "Dry labor is attended with a notable increase in the maternal and fetal hazard."

Edgar in his textbook on Obstetrics says that "premature rupture is not necessarily due to any intrinsic peculiarity of the membrane, but to anomalous conditions elsewhere (contracted pelvis, shoulder presentation). A certain proportion is thought to be of endometric origin. Early rupture of the membranes is of frequent occurrence but the condition is not invariably dystocic, because the amniotic fluid

*Read by invitation at a meeting of the Buffalo Academy of Medicine, January 18, 1921. 
does not necessarily all escape. When it is completely evacuated, the dystocic condition known as 'dry labor' develops. The loss of the water wedge before the completion of dilatation brings the head of the fetus in direct contact with the cervix. This tends to induce a tetanoid action of the uterus and works injury to the cervix. The latter becomes greatly elongated and its anterior lip often edematous. Laceration is very common. Compression of the fetal head causes a tendency to asphyxia and intracranial hemorrhage. The tetanoid action of the uterus combined with the edematous cervix retards the first stage of labor and exhausls the mother. Premalure rupture is greatly dreaded in anomalous presentations and contracted pelves,-conditions under which it is especially prone to occur. In such cases it contributes a further element of dystocia."

Williams in his textbooks, states concerning dry labor: "This accident occurs occasionally in primipara and not infrequently in multiparous women before the onset of uterine contractions and gives rise to what is designated as 'dry labor,' which is usually unduly prolonged and very painful. The delay is due in great part to the absence of the hydrostatic action of the bag of waters, in consequence of which the changes in the cervix must be brought about almost entirely by the presenting part, * * a dilating wedge of imperfect shape and consistency. This complication is usually not so serious in multiparous as in primiparous women, since in the former, labor, as a rule, sets in within a short time of the discharge of the liquor amnii. Occasionally, however, days, and in rare instances even weeks, may elapse before it occurs. *** The premature opening of the amnion greatly increases the danger of intrapartum infection."

Hirst: "If the membranes are too thin, they may rupture prematurely, and this gives rise to what is called a 'dry labor,' in which the birth canal must be dilated by the hard, unyielding presenting part instead of by the bag of waters. Such labors are longer and more painful than the average and there is greater likelihood in them of lacerations of the cervix and a more frequent demand for *** forceps."

The question thus not infrequently arises as to the duty to the patient with membranes ruptured, not in labor, or to the patient with membranes ruptured and in labor, when progress is slow and the cervix incompletely dilated. Does the drained uterus add material risk to the child? Can the danger from cord or body pressure be lessened by active interference? What is the increased liability to uterine infection from access of air to the drained uterus? From the lengthened labor? Does interference such as the use of the bag or bougie improve the results? To what extent is operative termination of these labors necessary?

To the authors it has seemed that the intensive study of cases of dry 
labor might be of value in fumishing a definite answer to some of these questions. For this analysis, a carefully kept record of a series of two thousand cases delivered at the Woman's Hospital was used. From these were selected all cases in which the membranes had ruptured twelve hours before delivery and in which the child had an intrauterine development of more than six and a half months. As it is recognized that ertain women whose labors start with ruptured membranes, with a dilated and dilatable cervix, have an expeditious labor, such eases were ignored.

From the two thousand histories there were collected two hundred and seventy cases of prematurely ruptured membranes in women with viable infants, in which the rupture occurred at least twelve hours before delivery. This gives us an incidence of clinically significant dry labor cases of 13.5 per cent. The proportion of primigravida was somewhat more than that of multigravida. This is in marked contrast to the general hospital ratio of five primiparæ to four multiparæ, showing a somewhat greater tendency to dry labor in primiparæ. It is possible that these figures indicate merely a greater probability of protracted labor in primipare when premalure ruplure oceurs.

The most constant factor in the causation of dry labor seemed to be deformities of the pelvis, of which there were $7+$ per cent of the whote. It is believed that a more careful study of the cases would have demonstrated a still larger proportion of pelvic abnormalities, as 39 per cent of the multiparæ gave a history of previous complicated labors. Four had had previous stillbirths. It seemed impossible to get any definite data as to the thinness of membranes or as to any pre-existing endometrial abnormality. Three of the cases were partial placenta previas, which might account for an irregularity in the tensile strength of the membranes.

Premature labors were 10 per cent of the whole, but as two-thirds of these were preceded by the ruptures, we cannot concede prematurity as frequently an essential cause for ruptured membranes. A maladjustment of fetal parts, such as breech or transverse, was found in 4 per cent of the cases. Twins occurred three times, which is about the normal incidence. Twice the membranes were ruptured by the introduction of bags, and once they were ruptured as a therapeutic measure in accidental hemorrhage.

As a possible condition favoring early rupture, it would seem that an unusual rigidity of the cervix, which is sometimes found in dry labor, might be the cause instead of the result of the acoidont. This tendency might also apply to a cervix cicatrized from previous injury or operation. A cervix that dilates prematurely, without labor, undoubtedly predisposes to premature rupture. But in the absence of other causes of dystocia, labor in these cases should progress with celerity. 
Our first study was of the relation of time of rupture to onset of labor. We found that approximately two-thirds of the cases (59 per cent) ruptured before labor; one-third (28 per cent) ruptured after the commencement of labor; and one-sixth (14 per cent) were reported to have rupture occurring with onset of pains. This gives us a ratio of $4: 2: 1$.

In the first classification there were found twenty-five eases where rupture had occurred from thirty to one hundred and twenty hours before labor pains. The average length of labor in these cases was computed and found to be ten and a half hours. One half were under eight hours. The length of time that the uterus remained drained did not particularly affect the duration of labor.

For purposes of comparison the average morbidity and fetal mortality of this class of cases is compared with other classifications.

All hospital cases

All cases of dry labor (270)

Cases with rupture $30+$ hours before pains (25)

Cases with rupture $30+$ hours before delivery (47)

Cases with $30+$ hours labor (53)

Cases with labor under 10 hours $(27)$

$\begin{array}{cc}\text { MORBIDITY } & \text { FETAL MORTALITY } \\ \% & \% \\ 17.5 & 5.5 \\ 26.0 & 8.4 \\ 20.0 & 8.0 \\ 19.0 & 8.5 \\ 34.0 & 15.0 \\ 27.0 & 5.0\end{array}$

In this connection the report of a private case is of interest. Mrs. H. E., thirty-nine years old. Previous labors, three: First 14 years ago, high forceps; second and third, low forceps, each followed by post partum hemorrhage. Date of expected labor, November 23, 1915. On November 26, the membranes ruptured. For four days there were no pains. Had the patient consented to hospital care I should, as was my custom at that time, have inserted a cervical bag. Under the circumstances, we simply delayed interference. November 30, four days later, pains commenced. Labor was normal up to the perineal stage, when forceps were used for inertia. Total labor, thirteen hours. The child was in good condition, weighing about nine pounds. The mother's recovery was without fever or other complications.

The second class of cases, i. e., those that ruptured after the onset of labor, showed thirteen cases of labor protracted to thirty hours or nore, fumishing 23 per cent morbidity and 15 per cent of fetal mortality.

Those cases rupturing with onset of pains gave 11 per cent of morbidity and no fetal mortality.

These figures bring us to the inevitable conclusion that the length of time that the uterus is drained is a negligible factor in the causation of morbidity or mortality; but that the length of labor is an important reason for both complications. 
Vaginal examinations, while offering a risk in all cases of labor, might be considered a greater menace in cases with ruptured membranes. All cases recording more than three vaginal examinations were studied-twenty-nine in all. The figures showed the starting morbidity of 52 per cent. The cases with no recorded vaginal examinations gave a morbidity of less than 25 per cent.

It is fair to state that in our morbidity figures all cases having a rise of temperature were included except those obviously explained by some cause other than pelvic. Thus every case of so-called "reactionary temperature" with a rise to $100.4^{\circ}$ F. is listed. Evidently the cases not examined were uncomplicated and less protracted.

The operative treatment of dry labor, aside from the termination of the cases, consists in the use of the Voorhees bag for induction of labor or as a substitute for the bag of waters in expediting dilatation. The bags were used in twenty-five cases. In eleven, the chief purpose was to induce labor. Four special indications for induction were: celampsia, toxic albuminuria, accidental hemorrhage, and placenta previa. In fourteen cases dilatation was desired in cases already in labor. Two of these had partial placenta previa.

In all bag eases the morbidity was 32 per cent; fetal mortality, 20 per cent. Cases with dry labor the only indication, 26 per cent; fetal mortality, 21 per cent. Contrast with all dry labors, morbidity, 26 per cent; fetal mortality, 8.5 per cent.

In so far as the figures from so few cases can be used as an index, the employment of bags did not reduce the maternal morbidity and appeared unfavorable to the safety of the fetus. Of the five children lost, three were deaths (one premature) and two were stillbirths, both premature. One prolapse of the cord occurred as a complication of the use of the bag but did not result in the loss of the fetus.

The termination of these bag labors results in eleven, or 44 per cent, of operative deliveries, as follows: forceps; 1 high, 4 medium, 5 low,and one cesarean, with hysterectomy for fibroid uterus.

The operative termination of all dry labors was 28 per cent, not ineluding breech deliveries.

The recorded average labor after the induction by bags was thirteen and three-quarter hours, with a pereentage of opcrative cndings of 54.5 per cent.

The study of the delivery of the dry labors brought out some interesting figures. If we include breech labors with our operative deliveries, nearly one-third of the births required artificial assistance. Sixty-four of the operations were forceps, five high, thirty medium, twenty-nine low. To these might be added two cases of the application of forceps to the after-coming head in breech deliveries. The indications as given were: deformed pelvis, 16 cases; inertia, 12; persistent occiput posterior, 12 ; over-sized child, 6; rigid cervix, twice; tonic 
uterus, once. In two cases, manual dilatation was employed, followed by a primary trachelorrhaphy.

The maternal morbidity was 28 per cent, with fetal mortality of 11 per cent, each 2 per cent higher than the average of the whole series of cases.

There were thirteen breech labors, two occurring in twin pregnancies and two in premature labors. The operations included two forceps, two breech extractions, one version from vertex for placenta previa, and one craniotomy on an after-coming head, with the child dead and the head held by a rigid cervix. Morbidity was 46 per cent; fetal mortality, 24 per cent. Lengthened dry labor in breech cases is therefore much morc scrious than in vertex cases. Furthermore, the proportion of breech labors in dry labors is more than twice the normal incidence.

The cesarean operation was used eight times,-for the following indications: six cases of disproportion, and two others with fibroids obstructing. There was one stillbirth in the case of a patient sent in with ruptured uterus. Two cases had a hysterectomy combined with the section, one with the ruptured uterus and one for fibroids.

Six of the eight patients had some temperature (one going as high as $105^{\circ}$ ) but all recovered. All these patients averaged over thirty hours with ruptured membranes. One case (No. 1176) had undergone forty hours labor and five vaginal examinations. At the time of operation the temperature was $101.4^{\circ}$. For ten days post partum there was fever, rising to $103^{\circ}$ as maximum.

Another case was a private patient, Mrs. B, thirty-nine years old, ipara. The membranes ruptured 36 hours before operation. There were two vaginal examinations. At the last, the eervix was high and thick, with the os admitting one finger. There was no evidence of pains. A flattened thickening to the left of the cervix showed a fibroid. When the uterus was incised, there was a distinct fetid or stale odor to its contents. The uterine cavity was swabbed with iodine, and the uterus and abdominal wall wcre closed without drainage. In the first twentyfour hours the temperature rose to $101.4^{\circ}$, and again on the sixth day to $101.2^{\circ}$. Otherwise recovery was normal, with primary union.

It is interesting to note in spite of the high morbidity that this series was free from maternal deaths. The inference would be that the drained uterus, even if existing for many hours, does not give the serious contraindication for Cesarean operation that has been maintained by many, especially if the examinations have been carefully used and other operative interference not attempted.

The study of the puerperal morbidity of our series gave 82 cases with temperature above $100.4^{\circ}$. From these we may subtract ten mastitis cases, leaving 72 cases in which we may ascribe fever to the labor. 
They were divided as follows: 56 sapremic or septicemic; 12 reactionary; 3 postoperative (after laparotomy); and one eclamptic.

Taking these 72 cases as the morbidity of the series, there is a total morbidity of 26 per cent, which compared with the average hospital morbidity of 17.5 per cent, gives us a fair estimate of the maternal increase of risk in dry labor. Excluding reactionary eclampsia and postoperative temperatures, the morbidity is 21 per cent.

Of the sapremic, 29 were nonoperative. In searching for possible reasons for fever, there were ten cases with labor over twenty hours; seven cases with membranes ruptured a considerable time before entering the hospital; four cases of post partum hemorrhage; and three cuses with several vaginal examinations.

Only eight of the sixty infected cases had fever above $102^{\circ}$; and the average duration of fever was eight days. These eighteen we might eall the seriously infected cases, one in fifteen. Three of them had no recorded vaginal examination, but had ruptured membranes some hours before admission. The other fifteen cases averaged three vaginal examinations. Eleven of them were operative deliveries. Three had post partum hemorrhages. Three of the eighteen had ruptured membranes before entering the hospital.

The one case of maternal mortality ruptured her membranes six hours after admission to the hospital,- twenty-five hours before delivery and eleven hours before labor. Two hours after the membranes ruptured, the patient had a chili. Following this, labor was induced by a bag. Twelve hours before delivery there was fever to $101.6^{\circ}$, inereasing to $102.6^{\circ}$ at delivery with pulse 148 . On the third day the temperature was $102^{\circ}$. The fever ran a septic course until the patient's death on the twenty-sixth day. The premature child, weighing four and a half pounds, died on the third day. At birth it had a temperature of $105.6^{\circ}$. Infection here would seem to have occurred before the introduction of the bag. It showed a remarkably rapid onset after the rupture of the membranes.

$\Delta \mathrm{n}$ example of intrauterine contamination with fever antepartum is illustrated in case No. 315, Mrs. A. K., para i. Membranes ruptured while at home. Eight hours later, pains began. Sixteen hours later she walked in the hospital. Pains were moderate, every twenty minutes. There was fever, $101.2^{\circ}$, pulse 104. An occiput posterior was manually corrected, with birth about an hour later. 'The baby was covered with foul-smelling vernix. Placenta and fluids from uterus were also offensive. The puerperium was normal, without fever.

In another case, Mrs. C., private patient, para iii, membrane had been ruptured for 48 hours, when bag was inserted. Birth of child followed expulsion of bag, 21 hours later. At the time of delivery the mother's Lemperature was $101.6^{\circ}$. She ran an irregular fever up to the twenty- 
first day, when a deep femoral abscess, due to phlebitis, was incised and drained.

The total mortality of 273 infants was twenty-three, or 8.4 per cent. This may be compared with the general hospital mortality of 5.5 per cent. There were eleven stillbirths, in which the probable causes contributing to death were: 4 forceps; 3 prolonged labors; 2 premature labors with placenta previa; 1 breech labor with rigid cervix; 1 unknown.

Of the twelve deaths, there were three forceps; six premature labors; two cases of atelectasis, and one congenital intestinal obstruction.

Dry labor therefore may be considered to increase the fetal mortality hazard three per cent.

In summarizing our conclusions, we should state that our deductions are necessarily confused by the fact that many of our cases had other reasons for prolonged labor, fever, and infant mortality than ruptured membranes. In other words, that obstetrical complications seem to be a cause for dry labor nearly as frequently as dry labor seems to be a cause for complicated labor.

It would seem established, however, by these figures that the length of time during which the membranes are ruptured before labor is not an important factor, either in prolonging labor or in producing morbidity or fetal mortality.

Protracted duration of pains in dry labor, on the other hand, greatly increased the morbidity and tripled the fetal mortality.

The morbidity risk inereased consistently in proportion to the number of vaginal examinations. There can be no doubt that every vaginal examination in the patient with ruptured membranes is a dangerous procedure. The rectal touch should be employed as much as possible.

The use of the dilating bag, even when employed to induce labor, did not reduce morbidity and seemed unfavorable to the fctus. With an operative termination in 54 per cent of such induced labors, and an average labor of over twelve hours, the question arises whether induction of labor by bags is justifiable.

Dry labor requires operative termination in one-third of the births.

The risks of breech labor are much greater if the membranes are ruptured early.

The cesarean operations in the series gave very good results, despite the grave prognosis usually given to abdominal hysterotomy in dry labor.

Finally, we may sum up the condition of dry labor as increasing puerperal morbidity 8.5 per cent and fetal mortality 3 per cent, the dangerous elements being prolonged labor, intrauterine contamination (usually from vaginal examinations), and the operative terminations.

133 EAST FIFTY-SEVLNIH STKEHT. 